\title{
Investigating the Impact of Climate Changes on Qualitative and Quantitative Growth of Oak Trees (Case Study: Central Zagros)
}

\author{
Morteza Habibi \\ Department of Forestry, Faculty of Science and Research, University of Islamic Azad, Tehran, Iran \\ Email: 1979@yahoo.com
}

Received 18 April 2016; accepted 16 May 2016; published 19 May 2016

Copyright (C) 2016 by author and Scientific Research Publishing Inc.

This work is licensed under the Creative Commons Attribution International License (CC BY). http://creativecommons.org/licenses/by/4.0/

cc) (7)

Open Access

\begin{abstract}
The present study is an attempt to investigate the impact of climate changes on quantitative and qualitative growth of oak trees in central Zagros region. After we selected the study region, 35 discs were taken from trees felled in each height class (e.g. $1400-1600,1600$ - 1800, 1800 - 2000 $\mathrm{m}$ above the sea level). We used climate index spi. For the data analysis, we employed SPSS software and inferential statistics tests of Kolmogroff Smirnov and the one-way ANOVA. During the recent 15 years, rainfall has shown a decreasing trend and amount of haze and frequency of occurring haze has been increased. The ANOVA results indicated that diameter growth of trees in three height classes revealed a significant difference. The average annual diameter growth in the first, second and third classes were $1.8 \mathrm{~mm}, 2.5 \mathrm{~mm}$, and $2.2 \mathrm{~mm}$, respectively. Additionally, the results indicated that hillsides and slope aspect has a statistically meaningful effect on the size of canopy area, basal area and number per hectare. Several different studies have reported that during the recent 15 years, qualitative and quantitative growth of central Zagros oak trees strongly correlate with climate parameters in the three habitats.
\end{abstract}

\section{Keywords}

Iranian Oak, Coppicing, Central Zagros, Diameter Growth, Slope, Elevation, Temperature, Rainfall, Haze

\section{Introduction}

Different species of oak trees have occupied a wide range of Hyrcanian, Arasbaran and Zagros forests. But, the maximum species diversity of oak tree is identified in the northern Zagros forests [1]-[3]. Three main species of oak consist of Quercus persica Jaub. \& Spach, Quercus infectoria, and Q. libani [4]-[7]. The northern Zagros 
ecosystem has changed under the influence of human activities with different intensity [8]. Common ownership, forests as national property, has caused appearance of a dichotomy along with national ownership [9]. However, intense dependency to forests because of livestock-based livelihoods, historical and cultural reasons and lack of alternative income sources, has made this dichotomy in the northern Zagros more challenging [10] [11]. An extensive range of local land use has been observed since the ancient times. This therefore has influenced structure and composition of forest as well as characteristics of the trees. As a matter of fact, severity and nature of these activities depend directly upon behaviors of traditional managers [12] Soil water 656 balance performs better than climatic water variables in tree species distribution 657 modelling (Global Ecology and Biogeography, 22, 470-482). But, some other parameters are influential, either [13] Patterns of forest 706 decline and regeneration across scots pine populations. Considering the points above, in the present study we analyzed physiographicfactors. Conducting a physiographic study is important due to its dual effects. Yet, such an investigation brings certain complexities together. In one hand, physiographic factors play a considerable role in quality and nature of habitat and on the other had they determine accessibility feature. This latter effect remarkably relates to how to treat lands. Habitats located over southern foothills are suitable environment for Quercus persica species. However, Q. Oliv. infectoria and Q. libani are prevailing species over northern and eastern foothills [8] [14] [15].

$Q$. infectoria and Q. libani species leaves are preferred to Quercus persica species for winter feeding of livestock as tree fodder. Therefore, exploitation of forests (lopping) is indirectly affected by physiographic factors. We expect that movement of livestock for pasturing most frequently takes place in topographically flat regions. Consequently, a few direct and indirect effects like reduced regeneration and increased soil composition would appear. In addition to management, physiographic factors control abundant ecological and silvic characteristics, in particular, light and soil moisture. These regulating characteristics belong to some important portion of quantitative and qualitative indexes of forest stands [16] [17]. Several different studies have discovered that structural features like diameter distribution and density as well as biometric characteristics of trees; i.e. diameter and height vary in different physiographic positions. [18] in a study naming "Persian oak habitat requirement in Chahar-Mahal Bakhtiari province forests", and [14] study titling "Q. infectoria habitat requirements in Kurdestan province" concluded that oaks are able to adjust with different physiographic positions (aspect, slope and elevation). But, every species of oak has a specific domain for an optimal appearance. For instance, presence of Q. infectoria in average slopes is more frequent than presence in other slopes.

[15] Investigated forests structure under local management in the northern Zagros. They realized that ground cover differs in various geographical aspects. However, certain characteristics including elevation and canopy area were not affected by this factor. [15] reported human activities and local management are the most prominent factors affecting biometric characteristics of trees in the region. In addition to the characteristics of trees, regeneration also changes in different physiographic circumstances. Due to significance of coppice as one strategy of oaks regeneration, specifically in arid areas [19] [20], examining the relationship between this regeneration system and physiography has drawn oak forests researchers' attention. [21] [22] measured the impact of physiogrpahy on sprout-clumps capability and sprout-clumps structure. The results showed that number of sprout in sprout-clumps, canopy area, tree height, and cross-section are differently influenced by slope, aspect, elevation and foothills shape. One fundamental reason for the effect of physiogrpahy on vegetation is difference between disturbance regimes controlling dynamism of forest stands in different physiographic positions [19]-[23].

Generally speaking, the physiographic factors have been considered as one of the most pivotal sources of change in forest ecosystems [16]-[24]. Despite difficulty in understanding this mechanism, due to interaction of various factors, a large portion of this effect appears as a result of controlling light and moisture regime [17]-[25]. The amount of nitrogen available in the soil for plants, which affects the amount of net production, is also influenced by topographic conditions [25] [26]. One reason for increasing complexity of investigating physiographic factors is presence of interactions between different related parameters. They encompass internal factors like slope, aspect, elevation, and position and external factors such as human effects influenced by accessibility (management), land use and ownership. [27] introduced a mathematical model showing the mutual effects of elevation, aspect and slope on regeneration models of forest species. Regarding to human presence and involvement in most of ecosystem types along with physiographic-ecologic effects, the past history of exploitation and land use play a substantial role in species composition and forest structure [28]. Reviewing the related literature has revealed that several different factors affect trees and stands characteristics. Therefore, the physiographic factors should not be known as the main source. 


\section{Methodology}

In the present study, we selected three major habitats, 1) foothills areas, 2) plain areas and 3) hills to measure the impact of habitat on diameter growth of tress. Some sprout-clump was selected randomly for each habitat. Then, we randomly selected a base from among numerous bases of each sprout-clump. Next, a disc was prepared and was tested in lab using loop and caliper. Conducting the current research, we employed the climate data driven from weather research center in the city during the recent 15 years. After we obtained the climate data, we extracted annual rainfall and annual temperature data of the central Zagros weather station during the recent 15 years. Additionally, we extracted and studied annual rainfall and annual temperature of the recent 4 years in which tree dieback was more frequent in the local forests. To do this, we used drought maps resulted from determination of drought indexes of the region reported by the weather station.

Furthermore, we analyzed data relevant to frequency of haze and its association to annual rainfall and annual temperature. The data were obtained from the Department of Environment in the province. Then, we prepared 35 discs of freshly cut stumps per each elevation. Using a binocular microscope of 1300 percent magnification, we measured the discs and diameter growth of annual tree rings. For this purpose, we applied SPSS software and statistical tests. The Kolmogorov-Smirnov test was utilized to test the data normality and a test of ANOVA for measuring significance of the data. In case, the variables were meaningful we used the Tukey test in order to compare the mean scores.

\section{The Study Region}

In the current research we selected three different habitats around Khoram Abad city. They included 1) foothills areas, 2) plain areas and 3) hills their characteristics are as follows:

-Shourab region (plain areas 1400 - 1600): The Shourab region is located at kilometer 17 Khoram Abad to Ahvaz road. The geographical location is $23^{\circ}$ and 25 minutes to $33^{\circ}$ and 25 minutes of north latitude, and $48^{\circ}$ and 11 minutes to $48^{\circ}$ and 13 minutes east longitude. This region lacks extreme terrains and the soil consists of rendzine, inceptisol, and alluvial soil (next to the Khoram Abad river). All local forests are also known as Shourab forest park. The total area of forests in the region is approximately 571 hectares. The common type of forests in the Shourab region is Persianoak; however, there exists minimal wood species diversity.

-GhaleGol region (hillhabitat 1600 - 1800): The GhaleGol region is located at a distance of $26 \mathrm{~km}$ south of the city. The geographical location is $33^{\circ}$ and 17 minutes north latitude, $48^{\circ}$ and 22 minutes to $48^{\circ}$ and 25 minutes east longitude. The common topographic shape is hill and local forests slope varies from $4 \%$ to over $100 \%$. The soil types of Ghale Golregion are inceptisols, entisols and vertisols. The Persian oak is the mostly common species in the region and Acer monspessulanum, wild pear, and hawthorn species compose other tree elements.

-Kaka Reza region (foothills, 1800 - 2000): The Kaka Reza forests are located at 45km northeast of Khoram Abad between $15^{\circ}$ and 48 minutes longitude and $52^{\circ}$ and 33 minutes latitude. The forests are in form of foothills, and the type of soil is calcareouslytus. In some areas brown and white soils can be seen. Different types of oak species cover the forest stand. The most common form of oak specie is Persian oak. Pistacia atlantica, hawothorn, Lonicera nummulariifolia Jaub \& Spach, Acer monspessulanum, Fraxinus excelsior, Paliurus spina and Vitexagnus-castus are other dominant species of the region.

In the present study, we selected and analyzed 35 samples (105 samples in total) from each habitat randomly. So, we had sufficient samples and we could generalize them to whole population. For sampling, first we selected a good forest stand and specified the place and domain. Then, we began sampling procedure in each region randomly. Next, we extracted coordinates of samples on the maps and highlighted them via GPS instrument. In each selected region, we determined the nearest sprout-clump as the sample and randomly selected a based from the shaping sprout. From the basal place of the base we extracted a disc. Subsequently, we sent the discs to the lab to be polished. Using loop and caliper, we assured parameters of age, diameter, basal area of the base and current growth of diameter (in 5 year periods) vey accurately and independently.

\section{Findings}

Table 1 shows number of extracted samples in terms of different classes. Table 2 represents descriptive statistics of quantitative characteristics of Persian oak. the results of measuring basal area diameter of trees with variance analysis shows that physiographic factors like slope and foothills aspect has a statistically meaningful effect on the basal area diameter of trees in 95\% level of confidence (Table 3). 
Table 1. Number of samples in terms of different classes.

\begin{tabular}{ccccc}
\hline Different aspects & West & South & East & North \\
\hline Number of samples & 35 & 35 & 35 & 35 \\
Slope classes (percent) & & $>50 \%$ & $\% 50$ & $\% 25$
\end{tabular}

Table 2. Descriptive statistics of quantitative characteristics of Persian oak.

\begin{tabular}{ccccc}
\hline Descriptive statistics Variable & Standard error & SD & M & N \\
\hline Basal diameter $(\mathrm{cm})$ & 0.31 & 14.2 & 35.2 & 2005 \\
Number per hectare (tree) & 1.63 & 18.92 & 75.89 & 180 \\
Basal area per hectare $\left(\mathrm{m}^{2}\right)$ & 0.19 & 2.21 & 8.75 & 180 \\
Canopy $\left(\mathrm{m}^{2}\right)$ & 0.04 & 2.09 & 4.12 & 2076 \\
\hline
\end{tabular}

Table 3. The results of the impact of foothills aspect and foothills slope on number per hectare of Persian oak.

\begin{tabular}{ccccc}
\hline Factor & $\mathrm{P}$ & $\mathrm{F}$ & $\mathrm{SS}$ & $\mathrm{df}$ \\
\hline Foothills aspect & $0.015^{*}$ & 6.005 & 1925.475 & 3 \\
Foothills slope & $0.013^{*}$ & 3.008 & 1212.57 & 3 \\
\hline
\end{tabular}

\section{Aspect and Slope}

Measuring the number of trees per hectare in different aspects revealed that north aspect difference with other aspects is meaningful. That is to say, there exists the minimum number per hectare. Additionally, measuring number of trees per hectare in different slopes indicated that slope holds a significant effect on number per hectare.

\section{Rainfall, Temperature, Haze}

According to Table 4, the average annual rainfall in drought periods shows a statistically meaningful variance and decrease compared with average rainfall in the recent 15 years. Comparing the average annual temperature in drought period with the recent 15 years indicated a meaningful difference. Moreover, the annual average number of days when haze took place showed a meaningful variance compared with the 15 year period. That is annual hazes has increased in the drought period.

As seen in Table 5, rainfall negatively correlates with temperature. That is, as rainfall decreased local temperature increased. Additionally, number of days haze happened showed a negative correlation with rainfall, while, positive correlation with annual temperature.

Elevation, Rainfall, Diameter

In this stage we analyzed the data and compared the mean scores of diameter growth of annual rings in three levels of elevation via the Tukey test. The results showed that a statistically meaningful variance $(P=0.05)$ exists between average diameter growth in three levels of elevation. The annual diameter growth in the first, second, and third levels are equal to $1.8 \mathrm{~mm}, 2.5 \mathrm{~mm}$ and $2.2 \mathrm{~mm}$, respectively. The results also suggest that the rate of precipitation within the recent 15 years holds a direct association with the rate of diameter growth. Additionally, the regression analysis of diameter growth of annual rainfalls and the rate of precipitation in three levels of elevation indicates a strong correlation between growth and rainfall.

Accordingly, diameter growth of oak annual rings in the study regions correlates together as follows. During years with high rate of rainfall the diameter growth of oak annual rings was significant. This confirms that the oak tree is moisture-friendly. Moreover, the chronological studies revealed that during the recent 15 years the rate of diameter growth associates with precipitation rate. Consequently, observing diameter growth recorded in the last years, we could track local climate changes (see Figure 1 and Figure 2).

\section{Discussion and Conclusions}

\section{Rainfall, Temperature, Haze}

Considering the present study, the findings showed that annual rainfall has decreased in the central Zagros within the last 15 years. However, this descending trend has been intensified during the recent 4 years. So that, 
Table 4. Mean scores of climate parameters in 4 year drought period vs. 15 year period.

\begin{tabular}{cccc}
\hline Period & Average haze days & Average annual temperature $\left({ }^{\circ} \mathrm{C}\right)$ & Average annual rainfall $(\mathrm{mm})$ \\
\hline 4 year drought period & 78 & 98.5 & 360.4 \\
15 year period & 37 & 70.9 & 502.9 \\
\hline
\end{tabular}

Table 5. Pearson's correlation coefficient test between climate parameters in the central Zagros region.

\begin{tabular}{|c|c|c|c|}
\hline Haze & Temperature & Rainfall & \\
\hline & & \multicolumn{2}{|r|}{ Rainfall } \\
\hline & & -0.287 & Temperature \\
\hline & 0.098 & -0.254 & Haze \\
\hline
\end{tabular}

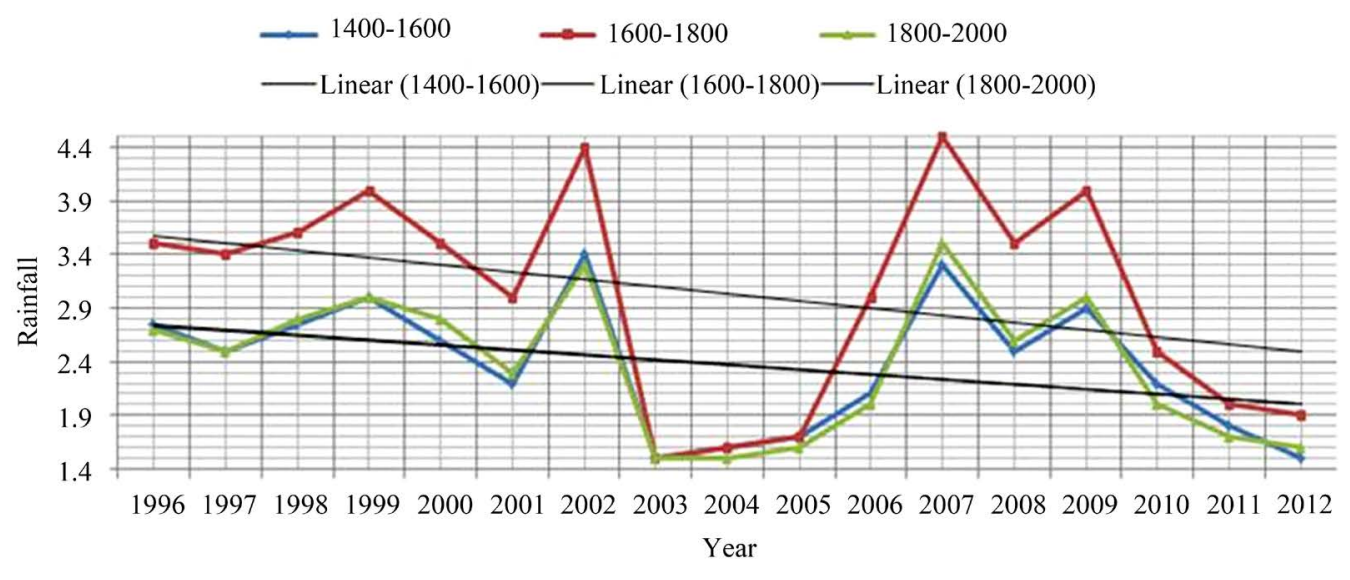

Figure 1. Relationship between elevation and rainfall.

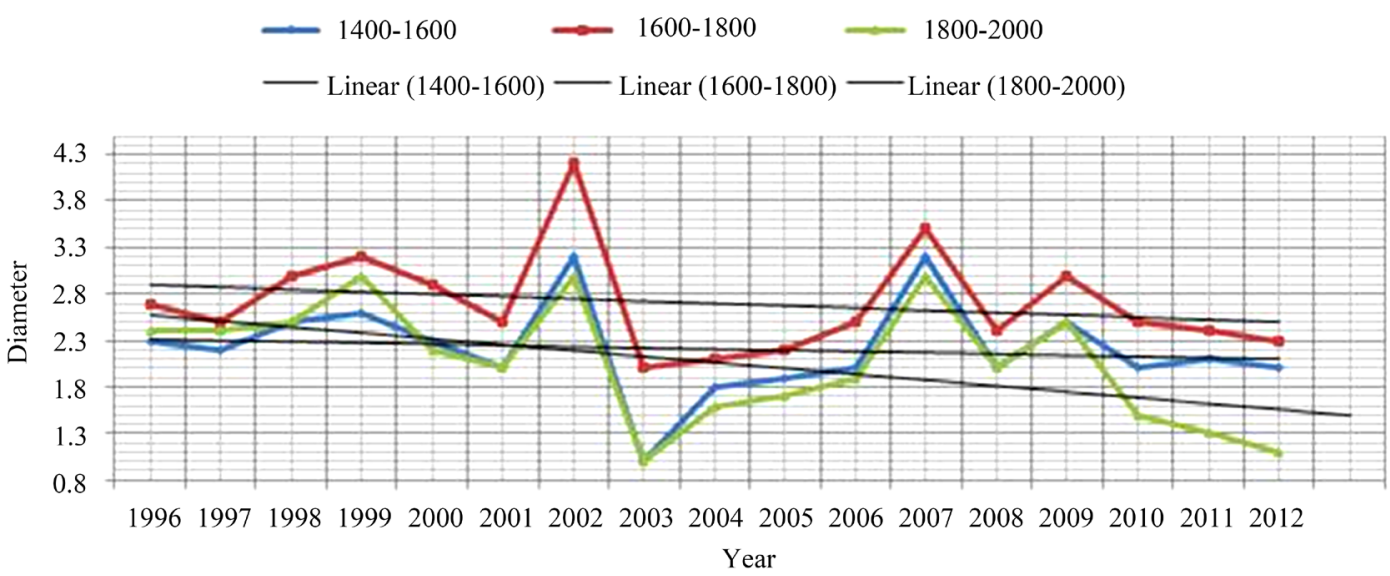

Figure 2. Relationship between elevation and diameter.

rainfall rate in this period showed a statistically meaningful, variance with the 15-year period. Furthermore, while rainfall rate has been decreased in the 15-year period, there has been a rise in temperature. Although, temperature increase was statistically insignificant, it indicated no meaningful difference with the drought period. Finally, we observed that along with reduced precipitation and increased temperature, haze frequently took place and it showed a negative correlation with rainfall, but a positive correlation with temperature. Generally speaking, with regard to the meaningful relationship between climate parameters and tree dieback, we concluded that in studies on tree reduction in local-regional sales or even larger, climate must be taken into account as one of the most fundamental effective parameters. 


\section{Elevation}

In lower (1400 - $1600 \mathrm{~m})$ and higher (1800 - $2000 \mathrm{~m})$ height due to ecological conditions and low temperature the diameter growth was slight and inappropriate. But, in medium height (1600 - $1800 \mathrm{~m})$, the growth rate was recorded greater than other two habitats. Moreover, after examining the growth rate of annual rings we found out that increase in elevation above sea level led to increase in diameter growth of annual rings. In medium height the average diameter growth of annual rings was recorded $2.5 \mathrm{~mm}$ at $\mathrm{P}=0.05$, which shows a statistically meaningful variance with other levels of elevation. The maximum diameter growth of annual rings in the medium height was $4.6 \mathrm{~mm}$ and the best elevation range in terms of qualitative and quantitative characteristics is 1600 - $1800 \mathrm{~m}$ above sea level. However, at elevation higher than $1800 \mathrm{~m}$, the diameter growth of annual rings decreased.

In the previouslyperformedstudiesusing42freshly cutstump from different regions of Baneh and Marivan habitats, the average diameter growth of annual rings was $3.2 \mathrm{~mm}$ [29]. [30] states that elevation has a spindle form effect on the growth rate of some species. Also, the results of studies on physical and mechanical changes of oak wood with respect to habitat revealed that despite wide annual rings oak wood showed better mechanical characteristics in the east Caspian region. But, Miyanb and oak wood with more porosity indicated better characteristics. [31] reports that oak species in middle height has better characteristics. In a study on wild pistachio habitat in Markazi province, the results showed that the species has better quantitative and qualitative characteristics in elevation 1845 - $2030 \mathrm{~m}$. Moreover, topographic features specially elevation affects the specie growth and quality [32]. Different investigations have reported that during the recent 15 years, when rainfall increased annual rings width has been wider and inverse. The figures illustrates that in these habitats, the maximum growth is in 1997 in middle height. The results further show that growth rate holds a direct and strong correlation habitat elevation and rainfall.

In middle height 1600 - $1800 \mathrm{~m}$, growth rate is greater than the other two habitats. The investigations have proved that elevation does not affect growth only. For example, anatomical studies of two Plantago major and Plantago lanceolata species in two different elevations of Behshahr city and Neka city at a height of $1280 \mathrm{~m}$ showed that elevation does increase the thickness of the cuticle and epidermal cells and the thickness of leafblade. Moreover, elevation increases root periderm thickness, parenchymal thickness of vessel length and diameter of the root [33]. The studies [34] indicate that the species is in areas is exactly exposed to humid and semi-humid-climate. More importantly, soil is more nutritious. Overall, combining climate and soil conditions has led to formation of pure types in higher elevations. While, in lower elevations the oak species is mixed with two other oak species.

Consequently, due to humidity and favorable soil conditions in valley species particularly in north as well as being moisture-like species, good conditions have been created for deploying the species in the valley. Therefore, compared with other species, oak is deployed in valley considerably. Various investigations have reported extensive distribution of the species in valley besides thick and high trees in this region. Examining the impact of aspect and rainfall on diameter growth of four forest species yellow poplar, red oak, red maple and chestnut, indicated that all species except for red oak showed a growth difference in northern and southern aspects. While, chestnut recorded less growth in northern aspect compared with the other three species. Generally, the maximum and minimum growth rate of the species in northern and southern aspects belongs to yellow poplar and red oak, respectively.

These results highlight dependency of some species to rainfall and accessible moisture, which play a remarkable role in deployment of some species and growth rate of annual rings. Considering the growth rate, thus we can anticipate the rainfall rate of the past years. In an investigation on juniper species diameter growth in three Layn, Firouzkouh and Zanjan habitats, the results were used to introduce some new strategies for studying climates [30]. The juniper species growth is influenced by several different factors like climate changes. So, annual frequency of favorable and unfavorable climate would be recorded in form of a sequence of wide and narrow rings in local tress. Due to possibility of reconstructing past climate changes and time periods obtained from this ecologically strategic mountainous region, we use them to detect climate changes. Totally, since oak is a moisture-like species and reacts towards climate changes, these transformations affect diameter growth of annual rings and as a result we can estimate rain fall rate through wide and narrow rings of oak wood.

One of the highlights of reforestation with species is taking habitat conditions into account. Since this species would not deploy in every habitat and every elevation. Thus, elevation is the most fundamental and influential factor on distribution of this species [35]. Therefore, serious activities must be taken to restore, develop and re- 
forest it. Furthermore, this species needs to be given special care because of its protection and support, aesthetics and economic values. This species in the study region protects from upper areas as well as economic contexts of lower areas. Otherwise, restoration and reconstruction of this species in local regions along with taking advantage from abundant benefits would be hard to achieve. Taking the above points together, we recommend that in reforestation with species, habitat conditions like elevation, different forms of soil and geographical aspects must be taken into serious account. As an example, the species in elevation lower than $1400 \mathrm{~m}$, compacted and disturbed soil are less deployed. The oak species is a species with limited transmittance. Therefore, in order for maintaining this genetic reservoir, serious steps need to be taken. One issue in protecting stands as well as establishment of caches for production of seed from mother bases with high quality is the problem of good habitats. Moreover, this species could be used in studies on climate and climate changes.

\section{Slope and Aspect}

Regarding to the field observations, the eastern foothills has exposed to less livestock pasturing due to its greater slope. Consequently, these regions have faced with less damage which positively influenced tree height. The results of trees basal area showed that the physiographic factors have no remarkable effect on basal diameter of the trees. Since approximately $75 \%$ of the Persian oak trees have a basal diameter lower than $50 \mathrm{~cm}$, the physiographic factors have a meaningful effect on the mean scores of the basal diameter in the all elevation levels. Further results of the basal area of trees per hectare indicated that aspect and slope significantly influence these characteristics. This result agrees with Razavi's results [36]. Intensity of solar radiation is slighter in the eastern and northern aspects and so it reduces temperature, evaporation and transpiration more significantly. As a result of this these regions are colder and are good places for development of this feature. Also, hillside aspect had no effect on number per hectare of the Persian oak. This could be because of light-like nature of the oak and its presence in all aspects, which shows ecologically broad domain. In the study region, the Persia oak trees have experienced dieback an alarm that they are in very critical and sensitive conditions [37]. However, we could not clearly describe the exact cause of Persian oak forests disappearance. As there exist lots of different unknown factors influencing such problem. Unfortunately, we may expect for disappearance of the Persian oak forests in other Zagros region. Accordingly, the present study can be regarded as a solution to preserving the oak species with better quantitative characteristics or regions are damaging.

\section{References}

[1] DjavanchirKhoie, K. (1967) Les chênes de l'Iran. Ph. D thesis. University de Montpellier, Faculté des Sciences, Montpellier, $223 \mathrm{p}$.

[2] Panahi, P., Jamzad, Z., Pourmajidian, M.R., Fallah, A. and Pourhashemi, M. (2012) Foliarepidermismorphology in Quercus (subgenus Quercus, Section Quercus) in Iran. Acta Botanica Croatica, 71, 95-113.

[3] Panahi, P., Jamzad, Z., Pourmajidian, M.R., Fallah, A., Pourhashemi, M. and Sohrabi, H. (2012) Folliar Epidermis Morphology in Quercus (Subgenus Quercus, Section Quercus) in Iran. Acta Botanica Croatica, 71, 95-113.

[4] McPherson, B.A. (2010) Responses of Oaks and Tanoaks to the Sudden Oak Death Pathogen after 8y of Monitoring in Two Coastal California Forests. Forest Ecology and Management, 259, 2248-2255. http://dx.doi.org/10.1016/j.foreco.2010.02.020

[5] Conrad, O.A., McPherson, B.A. and Wood S.R. (2010) Metabolite Profiling to Predict Coast Live Oak Resistance to Phytophthora ramorum. Poster Presented at the American Phytopathological Society, North Central Division Annual Meeting, 2012.

[6] Feau, N., Lauron-Moreau, A., Piou, D., Marçais, B., Dutech, C. and Desprez-Loustau, M.L. (2011) Niche Partitioning of Genetic Lineages Involved in the Oak Powdery Mildew Complex. Fungal Ecology, 5, 154-162. http://dx.doi.org/10.1016/j.funeco.2011.12.003

[7] Altman, J., Hédl, R., Szabó, Mazůrek, P., Riedl, V., Müllerová, J., Kopecký, M. and Doležal, J. (2013) Tree-Rings Mirror Management Legacy: Dramatic Response of Standard Oaks to Past Coppicing in Central Europe. PLoS ONE, 8, e55770. http://dx.doi.org/10.1371/journal.pone.0055770

[8] Fattahi, M. (1997) Habitat and Typology of Lebanon Oak in Iran. Research Institute of Forests and Rangelands, Tehran, 73 p.

[9] Besson, C.K., Lobo-do-Vale, R., Rodrigues, M.L., Almeida, P., Herd, A., Grant, O.M., David, T.S., Schmidt, M., Otieno, D., Keenan, T.F., Gouveia, C., Mériaux, C., Chaves, M.M. and Pereira, J. S. (2014) Cork Oak Physiological Responses to Manipulated Water Availability in a Mediterranean Woodland. Agricultural and Forest Meteorology, 184, 230-242. http://dx.doi.org/10.1016/j.agrformet.2013.10.004 
[10] Jazirehi, M.H. and EbrahimiRostaghi, M. (2003) Silviculture in Zagros. University of Tehran Press, Tehran, 560 p.

[11] Ghazanfari, H., Namiranian, M., Sobhani, H. and Mohajer, R.M. (2004) Traditional Forest Management and Its Application to Encourage Public Participation for Sustainable Forest Management in the Northern Zagros Mountain of Kurdistan Province, Iran. Scandinavian Journal of Forest Science, 19, 65-71. http://dx.doi.org/10.1080/14004080410034074

[12] Piedallu, C., Gégout, J.C., Perez, V., Lebourgeois, F. and Field, R. (2012) Soil Water 656 Balance Performs Better than Climatic Water Variables in Tree Species Distribution 657 Modelling. Global Ecology and Biogeography, 22, 470482.

[13] Vilà-Cabrera, A., Martínez-Vilalta, J., Galiano, L. and Retana, J. (2012) Patterns of Forest 706 Decline and Regeneration across Scots Pine Populations. Ecosystems, 16, 323-335.

[14] Maroufi, H. (2000) Site Demands of Lebanon oak (Quercus libani Oliv.) in Kurdistan Province. M.Sc. Thesis, Imam Khomeini Higher Education Center, Karaj, 95 p.

[15] Ghahramany, L., Ghazanfari, H. and Fatehi, P. (2009) Investigation of Structure of Oak Forests under Local Management in northern Zagros. 3rd National Conference on Forest, University of Tehran, Karaj, 11-13 May 2009.

[16] Barnes, B.V., Zak, D.R., Denton, S.R. and Spurr, S.H. (1997) Forest Ecology. 4th Edition, John Wiley \& Sons, Inc., New York, 774 p.

[17] Kaufmann, R.M. and Ryan, G.M. (1986) Physiographic, Stand, and Environmental Effects on Individual Tree Growth and Growth Efficiency in Subalpine Forests. Tree Physiology, 2, 47-59. http://dx.doi.org/10.1093/treephys/2.1-2-3.47

[18] Talebi, M., Sagheb-Talebi, Kh. and Jahanbazi, H. (2006) Site Demands and Some Quantitative and Qualitative Characteristics of Persian Oak (Quercus brantii Lindl.) in Chaharmahal \& Bakhtiari Province (Western Iran). Iranian Journal of Forest and Poplar Research, 14, 67-79.

[19] Oliver, D.C. and Larson, B.C. (1996) Forest Stand Dynamics. John Wiley \& Sons, New York, 520 p.

[20] Deljouyi, A. and Sadeghi, M.M. (2014) Long-Term Process of Climatic Parameters in West Oak Forests (SanandajKordestan). The 2nd National Student Conference of Forest Sciences, Scientific Student Association of Forestry of Tehran University, Karaj, 500-512.

[21] Pourhashemi, M., Marvi Mohajer, M.R., Zobeiri, M., Zahedi Amiri, Gh. and Panahi, P. (2007) A Study of the Factors Effective on Sprouting of Oak Species in Marivan Forests (Case Study: Doveyse Forest). Iranian Journal of Natural Resources, 59, 819-830.

[22] Soleymani, N., Dargahi, D., Pourhashemi, M. and Amiri, M. (2008) Effects of Physiographical Factors on Oak SproutClumps Structure in Baba-Koose Forest; Kermanshah Province. Iranian Journal of Forest and Poplar Research, 16, 467-477.

[23] Wyant, G.J., Alig, R.J. and Bechtold, W.A. (1991) Physiographic Position, Disturbance and Species Composition in North Carolina Coastal Plain Forests. Forest Ecology and Management, 41, 1-19. http://dx.doi.org/10.1016/0378-1127(91)90116-D

[24] Bale, C.L., Williams, J.B. and Charley, J.L. (1998) The Impact of Aspect on Forest Structure and Floristics in Some Eastern Australian Sites. Forest Ecology and Management, 110, 363-377. http://dx.doi.org/10.1016/S0378-1127(98)00300-4

[25] Griffiths, R.P., Madritch, M.D. and Swansona, A.K. (2009) The Effects of Topography on Forest Soil Characteristics in the Oregon Cascade Mountains (USA): Implications for the Effects of Climate Change on Soil Properties. Forest Ecology and Management, 257, 1-7. http://dx.doi.org/10.1016/j.foreco.2008.08.010

[26] Tateno, R. and Takeda, H. (2003) Forest Structure and Tree Species Distribution in Relation to Topography-Mediated Heterogeneity of Soil Nitrogen and Light at the Forest Floor. Ecological Research, 18, 559-571. http://dx.doi.org/10.1046/j.1440-1703.2003.00578.x

[27] Stage, R.A. and Salas, Ch. (2007) Interactions of Elevation, Aspect, and Slope in Models of Forest Species Composition and Productivity. Forest Science, 53, 486-492.

[28] Gerhardt, F. and Foster, R.D. (2002) Physiographical and Historical Effects on Forest Vegetation in Central New England. USA. Journal of Biogeography, 29, 1421-1437. http://dx.doi.org/10.1046/j.1365-2699.2002.00763.x

[29] Maaroufi, H. (2000) Studying Habitat Needs of Species in Kurdestan Province, MA Thesis of Forestry, Higher Education Institute of Imam Khumeini.

[30] Pourtahmasbi, K. (2001) Examining Quantitative and Qualitative Changes of Growth Rings of Juniper Trees in Three Iranian Habitats. PhD Dissertation of Wood Industry, Natural Resources Department, University of Tehran, Tehran.

[31] Ebrahimi, G. (1996) Studying Physical and Mechanical Changes of Oak Wood in Terms of Habitat. Journal of Natural Resources of Iran, 23, 17-49.

[32] Zahedipour, H., Fatahi, M. and Mirdavoudi, H. (2007) Examining Distribution and Quantitative and Qualitative Cha- 
racteristics of Wild Pistachio Habitats in Markazi Province, Saqez Mountain Region, Tafresh. Journal of Iranian Biology, 20, 191-199.

[33] Zarinkamar, F. and Marzban, A. (2010) The Impact of Anatomy of Two Plantago Major and Plantago lanceolata Speicies. Journal of Iranian Biology, 23, 532-540.

[34] Fatahi, M. (1977) Species Habitat and Typology in Iran. Research Institute of Forest and Shrubs of Iran.

[35] AtarRoshan, Y., Nasirpour, S., Derafshan, A. and Rajari, A.H. (2014) Investigating the Effect of Climatic Changes of Temperature and Oak Dieback Phenomenon in Khouzestan Province. The 2nd National Conference on Agriculture and Sustainable Natural Resources, MehrArvand Higher Educational Institute, Promotional Group of Environment Advocates, 121-138.

[36] Razavi, S.A. (2008) The Effect of Physiographic Factors on Quantitative Characteristics of Forest Types (Case Study; Vaz Research Forest). Journal of Wood \& Forest Science and Technology, 16, 121-134.

[37] Rahmani, Z. and Ghaderzade, H. (2014) Investigating the Effect of Climatic Factors on Oak Forests Reduction (a Case study of Kordestan Province). The 3rd National Conference on Iranian Natural Resources Researches with a Focus on Environment, Kordestan University, Kordestan, 718-732. 